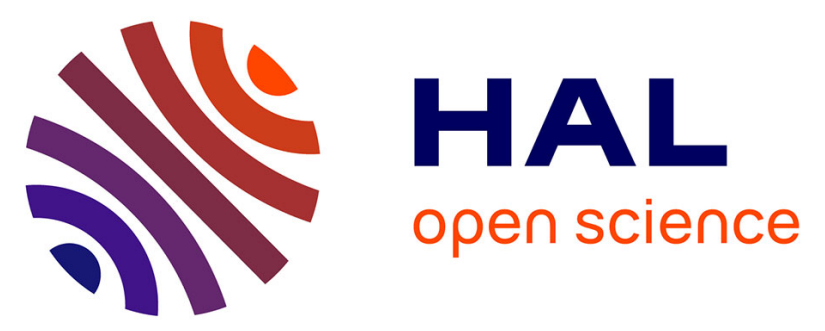

\title{
Model-Based Optimization of Semibatch Emulsion Polymerization of Styrene
}

Eduardo Schultz, Nida Sheibat-Othman, Alexander Mitsos, Adel Mhamdi

\section{To cite this version:}

Eduardo Schultz, Nida Sheibat-Othman, Alexander Mitsos, Adel Mhamdi. Model-Based Optimization of Semibatch Emulsion Polymerization of Styrene. Industrial and engineering chemistry research, 2020, 59 (37), pp.16368-16379. 10.1021/acs.iecr.0c02771 . hal-02941357

\section{HAL Id: hal-02941357 \\ https://cnrs.hal.science/hal-02941357}

Submitted on 28 Nov 2020

HAL is a multi-disciplinary open access archive for the deposit and dissemination of scientific research documents, whether they are published or not. The documents may come from teaching and research institutions in France or abroad, or from public or private research centers.
L'archive ouverte pluridisciplinaire HAL, est destinée au dépôt et à la diffusion de documents scientifiques de niveau recherche, publiés ou non, émanant des établissements d'enseignement et de recherche français ou étrangers, des laboratoires publics ou privés. 


\title{
Model-based optimization of semi-batch emulsion
}

\section{polymerization of styrene}

\author{
Eduardo S. Schultz ${ }^{\ddagger}$, , Nida Sheibat-Othman ${ }^{\ddagger}$, Alexander Mitsos ${ }^{\dagger, \S}$, Adel Mhamdi $^{\dagger}, *$ \\ ${ }^{\dagger}$ Process Systems Engineering (AVT.SVT), RWTH Aachen University, Forckenbeckstrasse 51, 52074 \\ Aachen, Germany
}

‡Laboratoire d'Automatique et de Génie des Procédés (LAGEPP) , CPE Lyon, CNRS, UMR 5007, Université de Lyon, Univ. Lyon 1, Villeurbanne, France

§JARA-Soft, 52056 Aachen, Germany

KEYWORDS: Dynamic optimization, Emulsion polymerization, Diffusion limitation, Semi-batch optimization

ABSTRACT: Emulsion polymerization reactors usually operate under starved conditions to better control the polymer properties and keep a safe operation. The main drawback is the low productivity obtained. In this work, we optimize offline the flowrates for semi-batch emulsion polymerization of styrene under starved conditions and keeping the reaction under diffusion limitation in order to maximize the reaction rate. To achieve this, we impose the maximal concentration of monomer in the particles as a path constraint. This results in a higher reaction rate compared to starved conditions close to saturation. At the same time, it enables safe operation by avoiding accumulation of monomer that may react hazardously at the end of the reaction, once the gel effect occurs. Therefore, we show that high 
productivity can be obtained by operating the reactor under starved conditions. We compare the optimal recipe under diffusion limitations with the benchmark of keeping the concentration of monomer in the polymer particles close to saturation and with constant feeding flowrates. We find consistent improvement of both the average reaction rate and the amount of polymer produced in the optimized strategy.

\section{INTRODUCTION}

Optimization and control of emulsion polymerization is a timely topic. Competition in the polymer industry implies that even a small improvement in process performance may strongly contribute to commercial success ${ }^{1,2}$. Challenges for optimization and control include the lack of online measurements, complex mathematical models, and different desired properties of the final products ${ }^{3}$.

Many of the emulsion polymerization reactions are run in batch or semi-batch ${ }^{4}$, and aim to maximize the polymer production rate, minimize the batch time, and obtain desired polymer properties. It is frequently necessary to use indirect measurements to control the polymer properties that cannot be measured online, such as the molecular weight or the particle size distribution (PSD $)^{5,6}$. Moreover, it is necessary to respect process constraints for safe operation, e.g., avoiding high temperatures that may result in thermal runaway. Dimitratos et al. ${ }^{7}$ present the main challenges in the control of emulsion polymerization reactors and Asua ${ }^{1}$ highlights the main topics of the field, including, among others, the development of mathematical models, new sensors and methods for online monitoring, and tools for control and optimization.

Mathematical models for emulsion polymerization are usually complex, with many parameters and rate coefficients that are difficult to obtain independently and accurately ${ }^{8}$. Moreover, simulation of these models must be fast and robust in order to be employed within online/offline optimization methods $^{9}$. Dynamic models have been employed by many authors ${ }^{4,10-16}$ to find optimal operation 
strategies of semi-batch reactors for styrene polymerization. The typical objective in optimization is to maximize the reactor productivity, while obtaining a polymer with desired properties and keeping a safe operation $^{4,10,17}$. In order to have a better control of the reactor temperature and the polymer properties, the reactor usually operates under starved conditions, which however results in low productivity ${ }^{18-20}$. The reduction in the reaction rate is usually due to the implementation of a small timeconstant monomer flowrate, which is calculated to avoid saturation at the beginning of the semi-batch period. Herein, we demonstrate that high reaction rates can be obtained under starved conditions by restricting the concentration of monomer in the particles.

Recently, Brunier et al. ${ }^{18}$ combined different models from literature for the second (saturated) and third (starved) intervals of emulsion polymerization of styrene and identified their parameters. The model consists of mass balances for monomer, polymer, initiator and emulsifier. It takes into account the evolution of the particle size distribution by growth and the gel effect as a function of the monomer concentration. Indeed, particle growth depends on the concentrations of monomer and radicals in the polymer particles. The concentration of radicals in the polymer particles, in turn, depends on radical capture by the polymer particles, radical desorption from the polymer particles to the aqueous phase and bimolecular radical termination by recombination within the particles. A decrease in the concentration of monomer is known to influence radical diffusion in the polymer particles, leading to a decrease in bimolecular radical termination, and in extreme conditions to the gel effect, where a high reaction rate is obtained. Therefore, operating under diffusion limitation can increase the reaction rate when compared to operation under saturated conditions. The authors ${ }^{18}$ provide a precise identification of this region.

In this work, we focus on the offline dynamic optimization of a semi-batch emulsion polymerization for the production of polystyrene taking into account the experimental findings in the work of Brunier et al. ${ }^{18}$. We determine optimal feeding rates of monomer that maximize the amount of product at a 
defined final time. In contrast to previous works in the literature ${ }^{4,10,11}$, we do not keep the concentration of monomer inside the particle close to the thermodynamic saturation limit. Instead, we control the reaction under diffusion limitation by maintaining this concentration below the limit identified by Brunier et al. $^{18}$. To achieve this, we introduce a path constraint in the optimization problem. Most control works neglect the diffusion limitations in the model and assume monodisperse particles, which lead to non-optimal operating conditions. We show that keeping the concentration of monomer in the particle at lower levels results in higher reaction rates than keeping it close to saturation as assumed by previous works ${ }^{4}, 10,11$. This is a particularly important result because it shows that it is possible to operate under starved conditions with high productivity by appropriately adjusting the monomer flowrate over time.

Additionally, the proposed strategy avoids the undesired gel effect in the end of the reaction. This is accomplished by keeping the operation under starved conditions (i.e. diffusion controlled) and achieving a high reaction rate that avoids the accumulation of monomer in the reactor. By avoiding the monomer accumulation, the safety of the reactor operation is enhanced. Indeed, in case of monomer accumulation in the reactor, soon or later its concentration will decrease, and the diffusion limitations will appear. In this case, the reactor still has a lot of monomer that will react suddenly, increasing significantly the reaction rate (usually called gel effect or Trommsdorff-Norrish effect), which can be dangerous.

We validate the optimal feed rates calculated by offline optimization of the dynamic model experimentally, i.e., we perform experiments using the optimized feed rates and compare with the expected results. We confine this work to offline methods and keep the investigation of an online optimization strategy for a future work. 
The remaining of this article is as follows. In Section 2, we briefly introduce the model of the process. We give in Section 3 a description of the experimental setup followed by the optimization scheme in Section 4. Section 5 presents the main results and a discussion. Finally, we give a summary and conclusions in Section 6.

\section{POLYMERIZATION MODEL}

We employ the detailed model described by Brunier et al. ${ }^{18}$ in the optimization. The model consists of a set of differential and algebraic equations that describe the broadening of the polymer particles during Phase 2 and 3 of emulsion polymerization of styrene. It assumes that the number of particles is constant, i.e., coagulation and nucleation of particles are avoided and it employs different reaction rate coefficients when the polymerization occurs under diffusion limitations. We present the model equations related to the reaction rate and diffusion limitation in Appendix $A$, and discuss the implication of the different rates for the optimization of the process. We provide the full Matlab ${ }^{21}$ model in the supplementary material.

\section{EXPERIMENTAL SETUP AND OPERATION MODES}

In all the conducted experiments, the monomer, styrene (Acros Organics, 99\% extra pure, stabilized) is stored in a fridge until use. Potassium persulfate (KPS, Sigma-Aldrich, minimum 99\%) is used as initiator and sodium dodecyl sulfate (SDS, Sigma-Aldrich) is used as surfactant. Deionized water of $18 \mathrm{M} \Omega \mathrm{cm}$ resistivity is used throughout the work. A $1 \mathrm{~L}$ reactor is used with mechanical stirring at $350 \mathrm{rpm}$ using a three blades Bohlender propeller. First, the surfactant is dissolved in water for $30 \mathrm{~min}$ under stirring in the reactor at ambient temperature and degassed using nitrogen. The mixture is next heated to $70^{\circ} \mathrm{C}$ using a thermostated bath and styrene is added. The polymerization initiates by adding $1.6 \mathrm{~g}$ of KPS. During the reaction, the nitrogen gas flow is moved upwards off the reaction medium to the top of the reactor to maintain saturation of the gaseous atmosphere with nitrogen. 
Figure 1 presents a flowsheet of the used laboratory setup. The system has two main controllers, where one controls the reactor temperature and the other the flowrate of monomer fed into the reactor. The flowrate is inferred from balance measurements of the monomer container and the desired flowrate is set manually. The temperature of the reactor is controlled by adjusting the setpoint of the bath temperature. The reaction is monitored by calorimetry that allows estimating the monomer conversion and the reaction rate online.

We investigate two different operation procedures, named "ab-initio" and "seeded". In the "ab-initio" operation mode, the polymerization reaction starts with a batch polymerization period during which polymer particles nucleation takes place and all the initial monomer is consumed. When the reaction stops, a sample is taken and the reactor is kept in the same operating conditions without any monomer feeding for one hour. During this time, the particle size distribution and the mass of polymer are measured in order to have an initial condition of the dynamic model, and thus be able to calculate the optimized flowrates. After one hour, the semi-batch reaction phase starts with the optimized flowrate of monomer to allow growth of the polymer particles. 


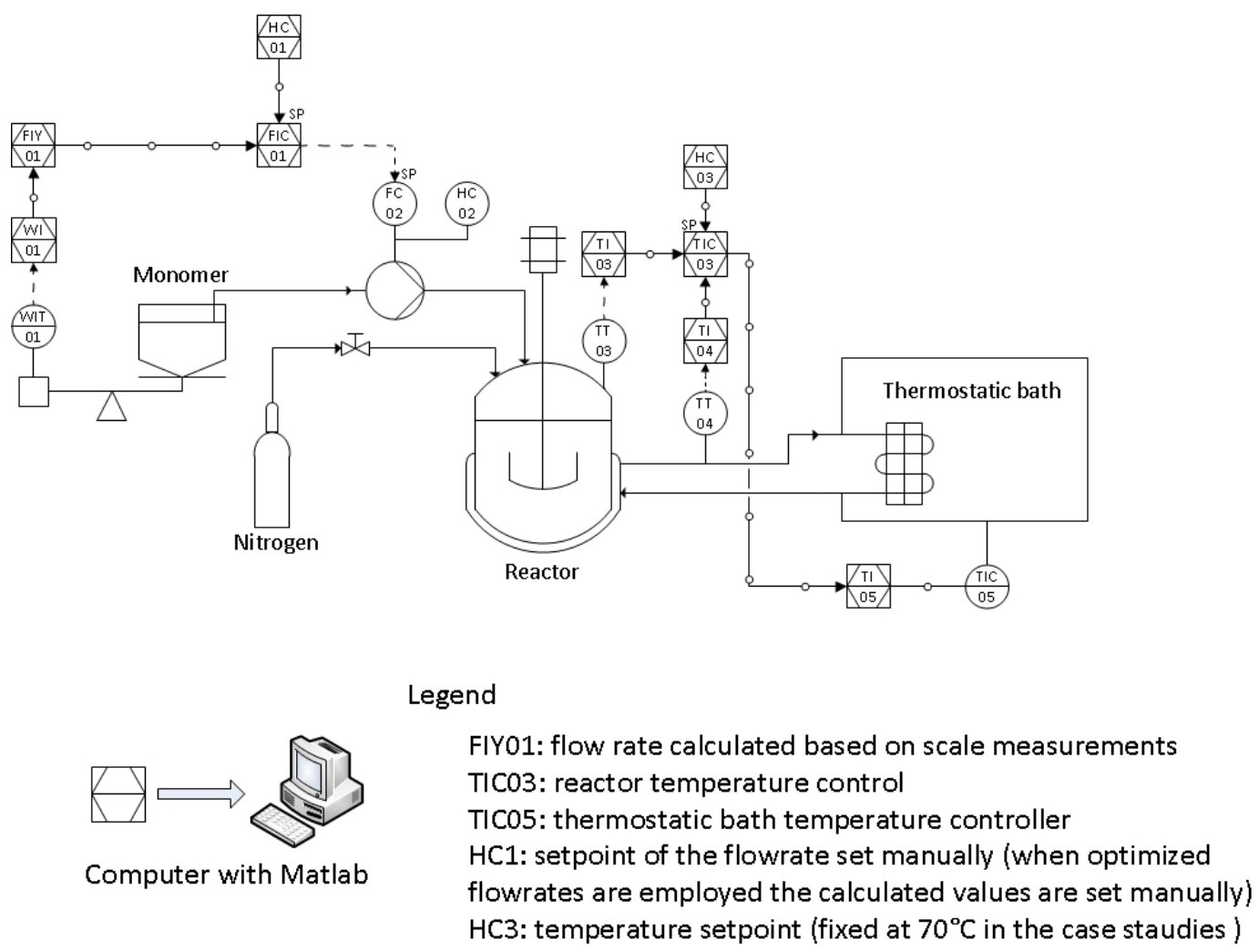

Figure 1: Flowsheet of the laboratory setup.

In the "seeded" operation mode, small polymer particles are generated first, following the same procedure described above. Then, the resulting polymer product is divided in several samples that are used as seeds for the semi-batch operation. The initial conditions of the system are obtained by analyzing the fraction of polymer (i.e. the solid content) and the particle size distribution of the generated seed. Since the second part of the reaction is run in another day, the feed flowrate does not start directly with the optimized flowrates, but with a constant small flowrate of monomer of $0.01 \mathrm{~g} . \mathrm{s}^{-1}$ for $30 \mathrm{~min}$ in order to ensure swelling of the polymer particles with monomer and effective initiation of the reaction. After this initial time, the monomer feeding flowrates calculated by optimization are employed.

4. OFFLINE DYNAMIC OPTIMIZATION 
The optimization problem maximizes the mass of polymer produced $m_{\mathrm{p}}$ at an a-priori fixed final time $t_{\mathrm{f}}$, by manipulating the feeding flowrate of monomer $F_{\mathrm{m}}$. The total amount of polymer produced is the integral of the polymer reaction rate over time. Thus, for a fixed amount of monomer and assuming complete conversion, an increase in the polymer reaction rate is equivalent to a decrease in the total reaction time. We could instead choose to explicitly minimize the reaction time, but we would then need to define the maximum amount of monomer added to the reactor (or the mass of polymer to be produced) as an endpoint constraint. In both problem formulations, the minimum time is achieved when the reaction rate over time is maximized ${ }^{11}$, still under the assumption of complete conversion of monomer.

The dynamic model calculates the reaction rate by different equations based on the system condition, i.e., there is one equation for starved conditions (for $[M]_{\mathrm{p}}<[M]_{\mathrm{p}}^{\text {sat }}$ ) and another for saturated conditions (for $[M]_{\mathrm{p}}=[M]_{\mathrm{p}}^{\text {sat }}$ ). Moreover, within the starved condition interval, at some concentration of monomer, diffusion limitations appear and the termination rate coefficient $\left(k_{\mathrm{t}}\right)$ is not constant anymore (see eq. (3) of Appendix A). For $[M]_{\mathrm{p}}$ higher than this limit, $k_{\mathrm{t}}$ is constant similarly as in the saturated interval. The condition, and consequently the reaction rate equation, changes according to the concentration of monomer in the particles $[M]_{\mathrm{p}}$. Higher reaction rates can be obtained under a diffusion limitation condition and Brunier et al. ${ }^{18}$ identified the onset of the diffusion limitations at $[M]_{\mathrm{p}}=3.3 \mathrm{~mol} \mathrm{~L}^{-1}$. This indicates that higher reaction rates can be obtained when $[M]_{\mathrm{p}}$ is lower than this onset value. Consequently, we tested different values of $[M]_{\mathrm{p}, \max }\left(3.3 \mathrm{~mol} . \mathrm{L}^{-1}\right.$ or $\left.2.5 \mathrm{~mol} . \mathrm{L}^{-1}\right)$ as a path constraint in the optimization problem in order to maximize the reaction rate and to make it robust to potential modelling errors, since the model predictions are not exact. We formulate the dynamic optimization problem described above as follows: 


$$
\begin{gathered}
\max _{F_{\mathrm{m}} \in F} m_{\mathrm{p}}\left(\boldsymbol{x}\left(t_{\mathrm{f}}, F_{\mathrm{m}}\right)\right) \\
\text { s.t. } \dot{\boldsymbol{x}}\left(t, F_{\mathrm{m}}\right)=\boldsymbol{f}\left(\boldsymbol{x}\left(t, F_{\mathrm{m}}\right), t, F_{\mathrm{m}}\right), \\
\boldsymbol{x}\left(t_{0}\right)=\boldsymbol{x}_{0}, \\
{[M]_{\mathrm{p}} \leq[M]_{\mathrm{p}, \max }, \forall t \in\left[t_{0}, t_{\mathrm{f}}\right],}
\end{gathered}
$$

where $F_{\mathrm{m}} \in F:=\left\{F_{\mathrm{m}, \mathrm{i}} \in \mathbb{R}^{n_{\mathrm{df}}}: 0 \leq F_{\mathrm{m}, i} \leq 0.3 \mathrm{~g}^{\mathrm{s}} \mathrm{s}^{-1}, i=1, \ldots, n_{\mathrm{df}}\right\}$ denotes the degrees of freedom of the optimization problem arising from control vector parametrization. The objective function is the mass of polystyrene $m_{\mathrm{p}}$ at the final time, $\boldsymbol{x}(t)$ represents the states that are computed from the model equations given by Brunier et al. ${ }^{18}$, which are briefly described in Appendix A. The initial conditions are denoted by $\boldsymbol{x}_{0}$. Eq (1.d) defines the path constraint corresponding to the maximum concentration of monomer in the polymer particles.

\subsection{Optimization Algorithm}

The optimization is performed using the algorithm proposed by Fu et al. ${ }^{22}$ that guarantees the inequality path constraints are not violated at any time during the operation. The optimization algorithm and the model are implemented in Matlab ${ }^{21}$ version 9.0.0.341360 (R2016a, win64), using the function fmincon as NLP solver, and ode15s as integrator .

The flowrates are discretized along the time by piecewise constant functions with a fixed interval of 10 min between the change of the flowrate. This time interval was chosen based on the settling time of the flowrate controller available in the laboratory setup. It takes the controller 2 min to change the flowrate from one setpoint to another, thus, using a 10-minutes interval keeps the feed rate at the desired setpoint $80 \%$ of the time. Additionally, we tested the optimization for half of this interval (5 min), and the simulation results predict just a small improvement in the final mass of polymer produced (less than $1 \mathrm{~g}$ ). 
Since we use local optimizers, good initial guesses are crucial. This is particularly important herein because the model is discontinuous and highly nonlinear. To obtain a good initial guess, we approximately calculate the flowrates that make $[M]_{\mathrm{p}}$ the closest possible to $[M]_{\mathrm{p}, \max }$ over time. More specifically, we first approximately determine the flowrate by considering one interval after another and testing discrete values of the flowrate. The idea of the initialization procedure is to keep the concentration of the monomer in the polymer particles close to the upper bound. This may indicate that using a simple controller to keep $[M]_{\mathrm{p}}$ at a desired setpoint by manipulating the feed rate would be an optimal solution. However, accurate online measurement of $[M]_{\mathrm{p}}$ is not available as well as precise control of the flowrate, resulting in possible violation of the constraint. Moreover, the optimization further improves the feed policy calculated by the initial procedure and violations of the path constraint occur when rigorous algorithms are not employed, thus, we employ the algorithm proposed by Fu et al..$^{22}$ to avoid violations.

\section{RESULTS AND DISCUSSION}

Two types of experiments are considered:

1) ab initio experiments where the seed is generated at the beginning of the reaction and, after a batch period, the optimized flowrates are implemented;

2) seeded experiments where a previously prepared latex is used and, after a semi-batch period at a constant monomer flowrate, the optimized flowrates are implemented.

Both types of experiments are practiced in industry, and for which the optimization strategy is adapted and implemented identically. Three experiments are thus realized. In the first (seeded) experiment, the objective is to demonstrate the main consequence of operating under saturated conditions, that is, a strong gel effect takes place when the feed stops and the concentration of 
monomer decreases below a critical value. In the second (ab initio) experiment, $[M]_{\mathrm{p}, \max }$ is defined as the value of $[M]_{p}$ that leads to the onset of diffusion limitations identified by Brunier et al. [1] (i.e., 3.3 mol. $L^{-1}$ ), thus keeping the system under diffusion limitations. Finally, in the third experiment, we demonstrate that the method can also be employed in seeded polymerization, but a more conservative $[M]_{\mathrm{p}, \max }$ is employed which is found to increase significantly the mass of polymer produced in a time period. Therefore, for both "ab-initio" and "seeded" strategies, optimal feed policies can be calculated by offline optimization. We compare the results of the second and third experiments with the benchmark of keeping $[M]_{\mathrm{p}}$ close to the saturation limit. Moreover, we show that using the same amount of monomer with an average constant rate results in less polymer produced during the semibatch operation.

\section{1 "Saturated" experiment}

We show in this experiment the main consequence of saturating the polymer particle with monomer, resulting in unsafe operation. In this case, the reaction is initiated with seeds produced in a previous experiment. The full initial conditions are given in Appendix B. The concentration of monomer in the particles is allowed to reach $[M]_{\mathrm{p}}^{\mathrm{sat}}=5.42 \mathrm{~mol} \cdot \mathrm{L}^{-1}$ and we show in Figure 2 the main results of the experiment.

Note that an arbitrary flowrate of $0.01 \mathrm{~g} \cdot \mathrm{s}^{-1}$ is first employed during $30 \mathrm{~min}$, and then the optimized flowrate sequence starts. This flowrate sequence leads to the saturation of the polymer particles, as estimated by the offline measurements and by calorimetry (Figure 2.b). The model predicts well the concentration of monomer until getting close to the saturation point, where it drifts away from the measured values. This might be due to the fact that a small error in the diffusion limitation parameters and the onset of diffusion limitations or in the measurements of the flowrate and particle size distribution may lead to big drifts after some time. Another model limitation is that it assumes a 
constant number of particles and neglects possible coagulation or renucleation of particles. The creation of new particles would affect both the concentration of monomer and the reaction rate. The coagulation of particles reduces the number of particles and the consequent change in their size would affect the rates of radical capture and desorption. However, measurements indicate almost a constant number of particles in all experiments. Further studies, not covered in this work, are required to determine if higher precisions are required in the measurements or to better identify the model parameters and the onset of the maximum concentration of monomer in the polymer particle to ensure working under diffusion limitations, thus to avoid fast radical termination and increase the reaction rate. 

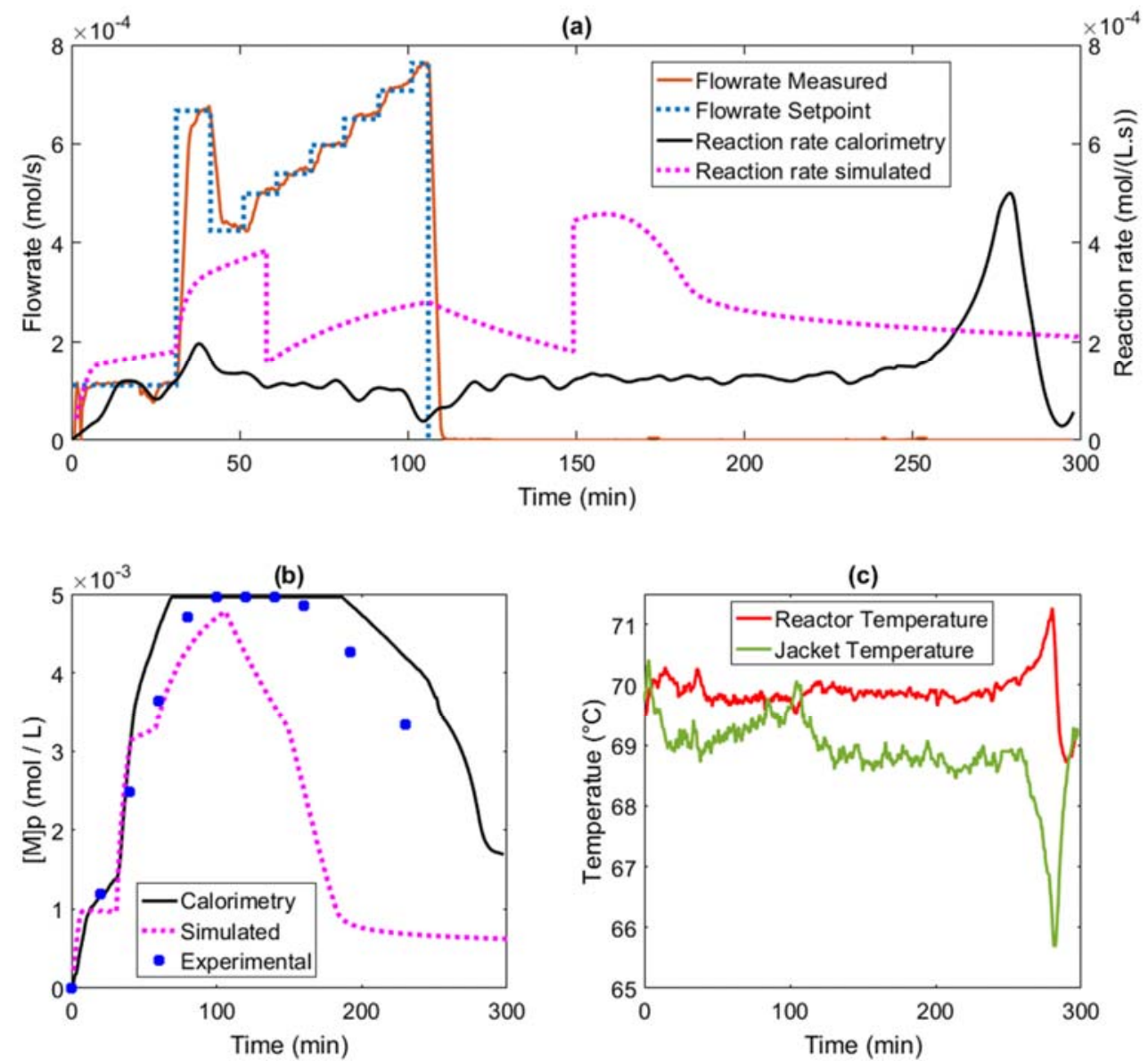

Figure 2: Results for the "saturated" experiment. (a) Reaction rate and flowrates measured online and their setpoints, together with the reaction rates calculated by the model (using the setpoints) and by calorimetry; (b) concentration of monomer in the particles; (c) reactor and jacket temperature profile.

Due to monomer accumulation, we observe a peak in the reaction rate $150 \mathrm{~min}$ after the flowrate has stopped, indicating that the accumulated monomer in the reactor reacts quickly due to the gel effect. In order to remove the energy generated during the occurrence of the gel effect, the reactor cooling system needs to be oversized. This is even more critical in an industrial case because the heat exchange area per unit volume is smaller in big reactors and the dynamics of the jacket temperature slower. Therefore, this operation policy likely becomes unsafe in an industrial size reactor, considering the abrupt increase of the temperature, shown in Figure 2.c. In this case, the change in the temperature is 
only $1 \mathrm{~K}$ because the reactor is small and the heat removal capacity of the reactor is high. Nevertheless, the temperature controller is not able to keep the temperature controlled during the peak in the reaction rate. This can be seen in Figure 2.c. by a significantly decrease in the jacket temperature. Therefore, this would result in a much larger variation in the temperature in an industrial case, where heat removal capacity is lower, in view of the reduced surface to volume ratio of the reactor.

\section{2 "Ab-initio" experiment}

In this experiment, the polymerization reaction is initiated without any seed (the full initial conditions are described in Appendix B) and the experimental procedure is divided in three phases. In the first phase, an initial batch is performed, where the polymer particles are generated. When the online calorimetry indicates that this reaction period is finished (i.e., the reaction rate gets back to zero), a sample is taken. The second phase is the period required to analyze the sample and calculate the optimal feed flowrates. During this time, we measure the mass of polymer in the system (by gravimetry) and the particle size distribution (by dynamic light scattering), providing initial conditions for the model. We simulate the system from the time that the sample is taken to the time the feed should start. This allows accounting for initiator decomposition that continues to take place even though there is no polymerization. The dynamic optimization problem (1) is solved to calculate the flowrates, restricting the maximum concentration of monomer in the particle to below 3.3 mol. $\mathrm{L}^{-1}$ along the entire semi-batch part. The computed feeding policy is implemented and the third phase of the experiment starts.

We show the different phases of the experiment in Figure 3.a, together with the reaction rate along the entire operating time, measured by calorimetry and calculated by the model. No peak is observed in the reaction rate after the flowrate stops. We recall that in the "saturated" experiment the reaction rate keeps an average value between 1.0 and $2.0 \times 10^{-4} \mathrm{~mol} \cdot \mathrm{L}^{-1} \cdot \mathrm{s}^{-1}$ during and after the feed and it undergoes a hazardous gel effect at the end of the reaction. In this experiment, the reaction rate is as 
high as $3.0-4.0 \times 10^{-4} \mathrm{~mol} . \mathrm{L}^{-1} . \mathrm{s}^{-1}$ during the feed, and decreases to almost zero when the flowrate stops. Thus, it is possible to keep the reactor operating at a much higher reaction rate for a long time.
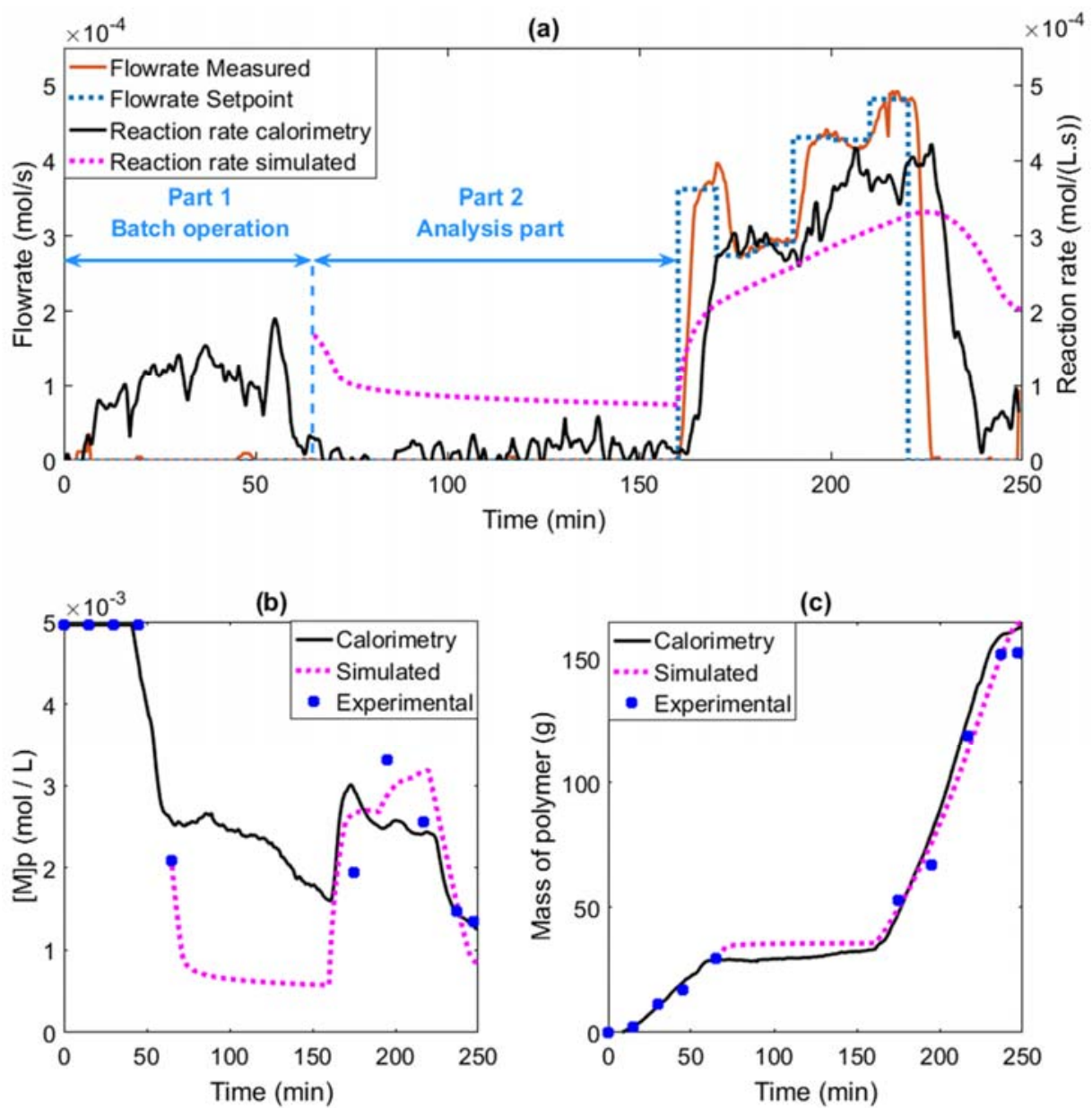

Figure 3: Results for the "ab-initio" experiment. (a) Reaction rate and flowrates measured online and their setpoints, together with the reaction rates calculated by the model (using the setpoints) and by calorimetry; (b) concentration of monomer in the particles; (c) mass of polymer along the time.

In Figure 3.c, we show the mass of polymer along the operation, comparing the results of the model with the ones calculated by calorimetry and the offline measurements made using the samples taken during operation. The model shows a much better agreement with the measurements when compared to the previous case where there is accumulation of monomer. However, Figure 3.b shows that the concentration of monomer in the particles does not have a good agreement between the calculated 
concentration based on the samples, calorimetry and by simulation of the model. Even though, only one sample at about $180 \mathrm{~min}$ seems to violate the constraint of $[M]_{\mathrm{p}, \max }=3.3 \mathrm{~mol} \cdot \mathrm{L}^{-1}$.

We present in Figure 4 the reaction rate obtained by the optimized flowrates with a simulation for the benchmark case $\left([M]_{\mathrm{p}}\right.$ close to $\left.[M]_{\mathrm{p}}^{\mathrm{sat}}\right)$ and for an average constant feed rate $\left(3.8 \times 10^{-4}\right.$ mol.s $\mathrm{s}^{-1}$, average of the optimized flowrates over time). Note that the comparison is for the semi-batch period (time between 160 and $220 \mathrm{~min}$ ). The graphs of Figure 3 present the results until the time $250 \mathrm{~min}$ to show that the reaction rate quickly drops after the feed stops, i.e., the reactor is operating in a safe region, where no peak in the reaction rate occurs when the flowrate stops. However, we assume that operation finishes at time $220 \mathrm{~min}$ and all unreacted monomer inside the reactor is lost. We see that the flowrates calculated by optimization give approximately a $47 \%$ higher reaction rate than the benchmark and the mean flowrate. The actual mass of polymer produced during the semi-batch period with optimized flowrates is $95 \mathrm{~g}$ (calorimetry) while the model predicts a production of $78 \mathrm{~g}$. Simulating the operation for the other two flowrate policies, we obtain $56 \mathrm{~g}$ of polymer for the mean flowrate and $59 \mathrm{~g}$ for the benchmark, demonstrating a good improvement that can be obtained by optimal feed policies.

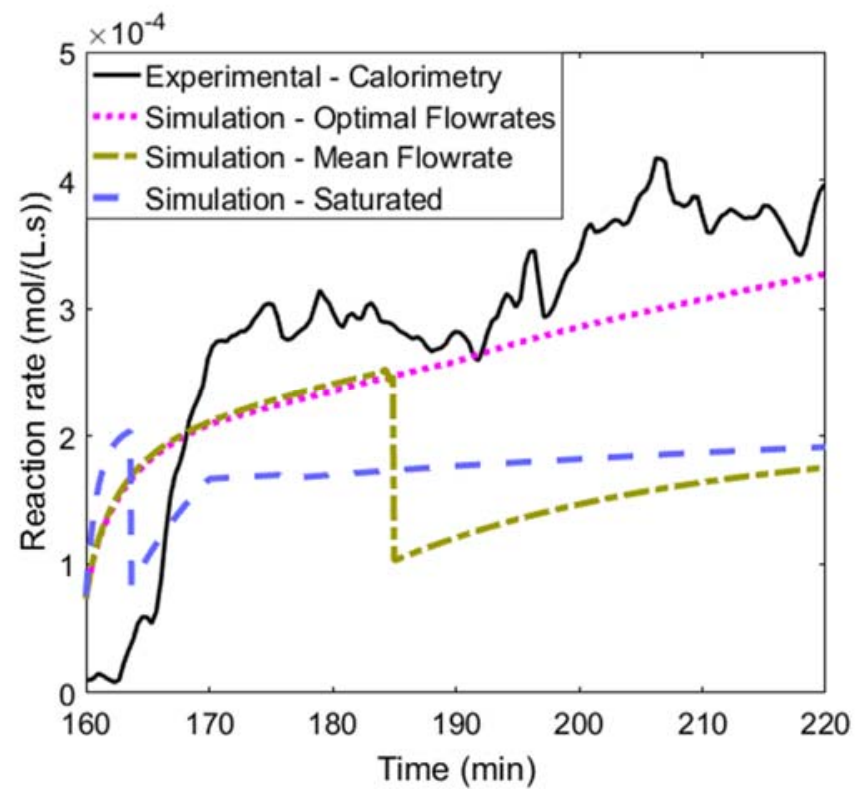


Figure 4: Comparison of the reaction rate obtained in the experiment with the simulated ones for a constant flowrate (average of the optimized ones) and a high flowrate that saturates de system for the "ab-initio" experiment.

\section{3 "Seeded" experiment}

In this experiment, the polymerization reaction is initiated with seeds obtained from a previous batch experiment (the full initial conditions are described in Appendix B). The initial conditions differ from the previous experiment, mainly in terms of the PSD, which allows evaluating the methodology for a wide range of properties and conditions. Initially, the system is activated by a small feed flowrate of $0.01 \mathrm{~g} \cdot \mathrm{s}^{-1}$ for $30 \mathrm{~min}$ (in order to ensure swelling of the polymer particles and reaching steady state in $R_{\mathrm{p}_{\mathrm{p}}}$ ), and then the optimal feed flowrate starts. The maximum concentration of monomer in the particles is restricted to $[M]_{\mathrm{p}, \max }=2.5 \mathrm{~mol} . \mathrm{L}^{-1}$. A lower value (than that of the onset of diffusion limitation) is employed because in the previous experiment, "ab-initio" in Section 5.2, the reaction rate decreased to a lower value when $[M]_{p}=3.3$. Therefore, a lower limit should guarantee that the system operates the entire operation time under diffusion limitation, lower radical termination, and higher reaction rate. In this case study, the semi-batch period is from time 30 to $110 \mathrm{~min}$, and we compare the reaction rate and the mass of polymer produced only during this period.

Figure 5 presents the main results of the experiment, showing that the system does not saturate during the feed period and that there is no peak of reaction rate after the feed stops. Moreover, the reactor operates at a higher reaction rate during the semi-batch time in this case $\left(R_{\mathrm{p}_{\mathrm{p}}}=4.0-5.0 \times\right.$ $10^{-4}$ mol. $\mathrm{L}^{-1} \cdot \mathrm{s}^{-1}$ with $\left.[M]_{\mathrm{p}, \max }=2.5 \mathrm{~mol} . \mathrm{L}^{-1}\right)$ than with $[M]_{\mathrm{p}, \max }=3.3 \mathrm{~mol} \cdot \mathrm{L}^{-1}\left(R_{\mathrm{p}_{\mathrm{p}}}=3.0-4.0 \times 10^{-4}\right.$ mol. $\left.\mathrm{L}^{-1} \cdot \mathrm{s}^{-1}\right)$. This is due to the higher diffusional limitations of radicals in this region that may not meet and terminate, which increases their number and therefore the reaction rate. 
For this lower concentration of monomer in the particles, the results of the model are closer to the calorimetry as well as to the offline samples analysis, as shown in Figure 5.b. This indicates that the modelling error is mainly due to an error in the onset value of $[M]_{\mathrm{p}}$ for diffusion limitations.
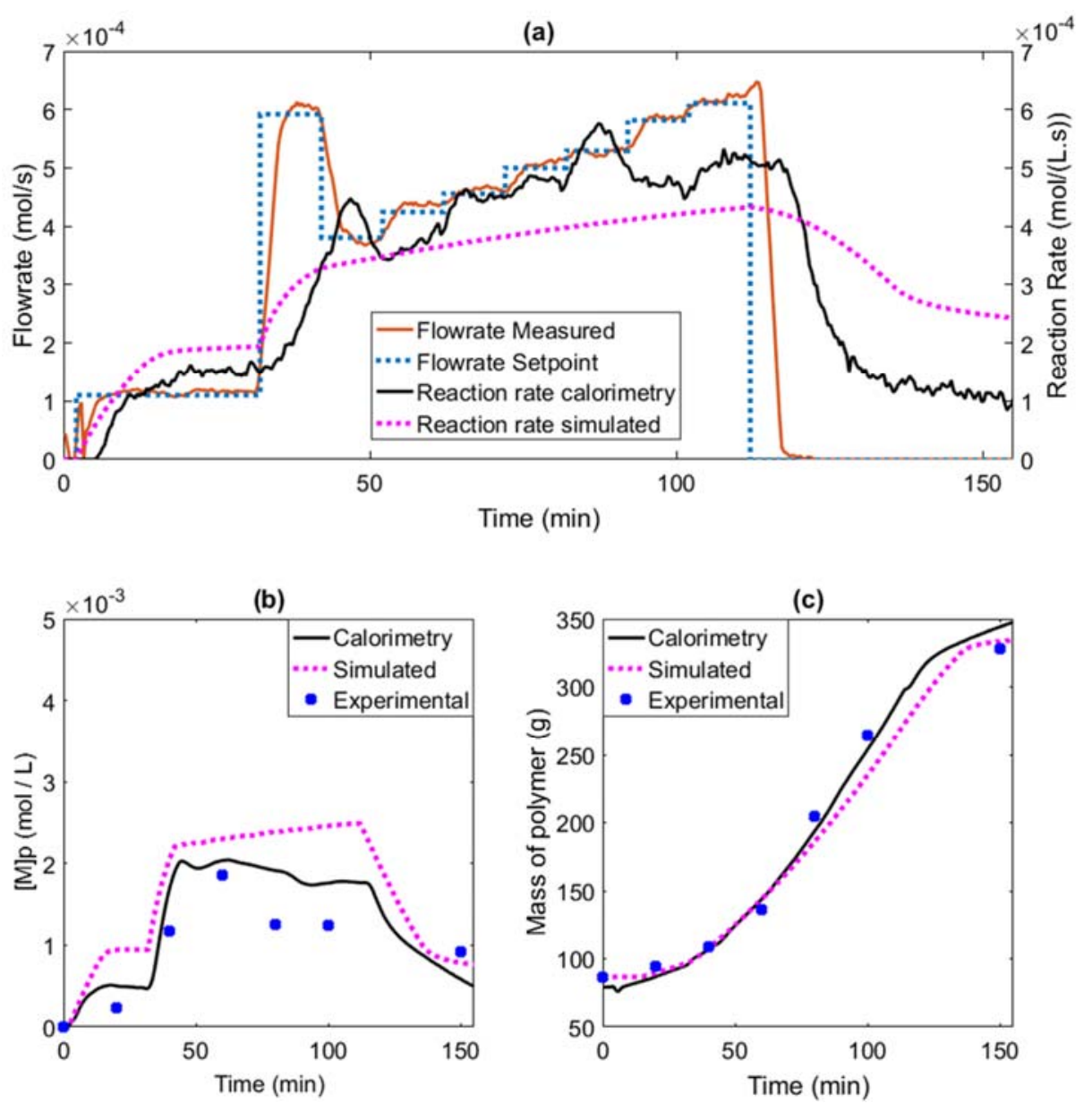

Figure 5: Results for the "seeded" experiment. (a) Reaction rate and flowrates measured online and their setpoints, together with the reaction rates calculated by the model (using the setpoints) and by calorimetry; (b) concentration of monomer in the particles; (c) mass of polymer along the time.

We compare again the reaction rate for the optimized flowrates with the simulation for the benchmark case $\left([M]_{\mathrm{p}}\right.$ close to $\left.[M]_{\mathrm{p}}^{\text {sat }}\right)$ and for an average constant feed rate $\left(4.0 \times 10^{-4}\right.$ mol.s ${ }^{-1}$, which is the average of the optimized flowrates over time). Figure 6 shows the curves for the different flowrates and the experimental one for the optimized flowrates showing again that the optimized 
flowrates keep the reaction rate at higher levels during the semi-batch operation, except in the initial minutes.

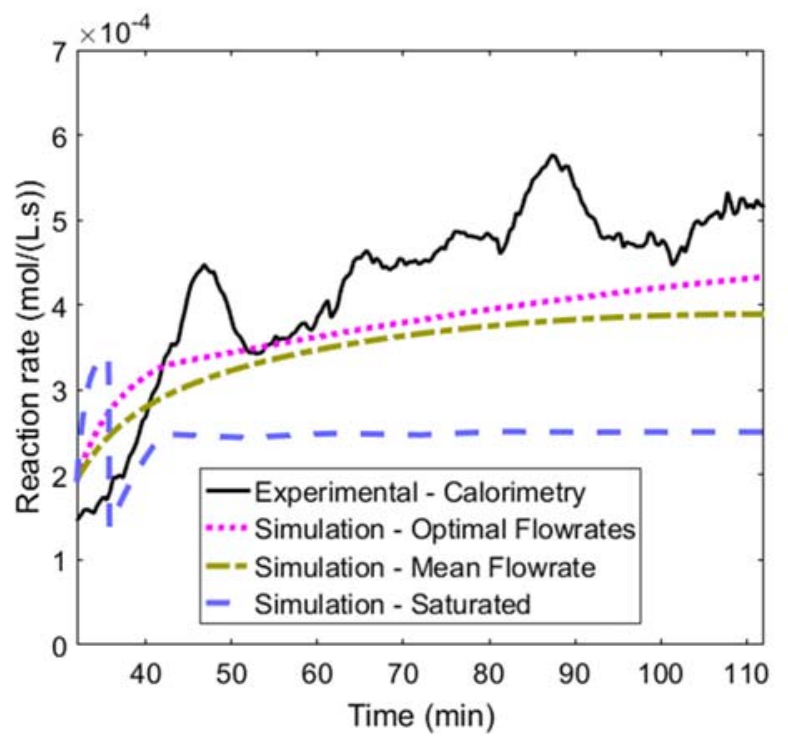

Figure 6: Comparison of the reaction rate obtained in the experiment with the simulated ones for a constant flowrate (average of the optimized ones) and a high flowrate that saturates the system for the "seeded" experiment.

The average reaction rate over the semi-batch operation is approximately $7.2 \%$ higher than using an average flowrate, and $51 \%$ higher than the flowrates that maintain the system close to saturation. In this case, the average flowrate keeps the system under diffusion limitation during the whole operation time, what did not happen in the previous case. By keeping the system under diffusion limitation, the average flowrate provides a reaction rate close to the one obtained by the optimized flowrates (as shown in Figure 6), reducing the relative gain of the optimized flowrates, although still significant. The mass of polymer produced for the optimal feed, between time 30 and $110 \mathrm{~min}$, is $190 \mathrm{~g}$, and the model predicts a production of $170 \mathrm{~g}$. Simulating the system for the benchmark case and average flowrate, we obtain a mass of polymer of $128 \mathrm{~g}$ and $154 \mathrm{~g}$, respectively. 


\subsection{Summary of results}

We observe that the model has almost no error in interval III under starved conditions. The main error appears when we get close to the onset of diffusion limitations and under saturated conditions, as shown in (Figure 2). The reaction rate calculated by the model for the first experiment (under saturated conditions) is in significant disagreement with the measurement. This error can be due to the onset value of the diffusion limitations $\left([M]_{\mathrm{p}}=3.3 \mathrm{~mol}^{-\mathrm{L}^{-1}}\right)$ or an experimental error in the residual amount of monomer. Only a small error in one of these values may lead to an accumulation of monomer in the reactor, leading to a big error in the model results. A more robust measurement, by Raman spectroscopy for instance, would be of great help to have a higher precision in the residual amount of monomer.

Another possible justification for this behavior is that the pseudo-bulk equation, used to calculate the number of radicals per particle $(\bar{n})$, might not be appropriate. Indeed, the pseudo-bulk equation is valid for large number of radicals per particle ${ }^{24}$, i.e. when $\frac{\rho_{e}}{c} \gg 1$ or $\frac{k_{d e s}}{c} \gg 1 . \bar{n}$ varied between 2.47 to 29.6 for the controlled experiments, where the system is forced to work under diffusion limitations (an average of 5.76 for the ab initio experiment and 20.8 for the seeded experiment). However, the values of $\bar{n}$ obtained under saturation conditions are between 0.70 and 1.82 with an average of 1.12 along the feeding period. The increase in $\bar{n}$ is expected under starved conditions as diffusion limitations reduce radical termination. This constitutes the driving force leading to an increase in the reaction rate in this work. Table 1 indicates the values of $\rho_{\mathrm{e}}, k_{\mathrm{des}}$ and $c$. It is clear that the pseudo-bulk equation is appropriate for the experiments under diffusion limitation, but not for the first experiment that is close to the limit of validity of this model.

Table 1: Mean value and range of $\rho_{\mathrm{e}}, k_{\mathrm{des}}$, and $c$ during the feed period of each experiment.

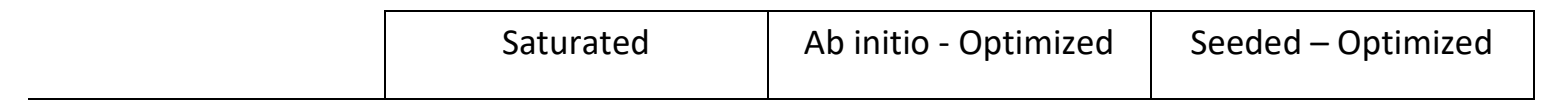




\begin{tabular}{|c|c|c|c|}
\hline$\rho_{\mathrm{e}}\left(\mathrm{s}^{-1}\right)$ & $57(52-78)$ & $43(35-53)$ & $76(69-93)$ \\
\hline$k_{\mathrm{des}}\left(\mathrm{s}^{-1}\right)$ & $0.077(0-0.3)$ & $0.038\left(7.8 \times 10^{-5}-0.050\right)$ & $0.0083(0-0.017)$ \\
\hline$c\left(\mathrm{~s}^{-1}\right)$ & $66(20-100)$ & $9-24(18)$ & $2.6(1.4-4.3)$ \\
\hline$\rho_{\mathrm{e}} / c(-)$ & 1.16 & 2.39 & 29.2 \\
\hline$k_{\mathrm{des}} / c(-)$ & 0.0014 & 0.0021 & 0.0032 \\
\hline
\end{tabular}

Note that the suggested changes in the reaction rate may influence the polymer molecular weight within a certain limit. In this work, the impact on the polymer molecular weight was not measured. However, it was found in a previous work ${ }^{17}$ that changing the concentration of monomer in the polymer particles leads to a negligible change in the polymer molecular weight in the case of styrene (while a higher impact was observed for methyl methacrylate). However, in case the polymer molecular weight is also to be controlled, we need to extend the optimization strategy and use additional manipulated variables, like temperature ${ }^{25}$ or chain transfer agent ${ }^{1,26}$, to control both the reaction rate and the polymer molecular weight. For instance, Plessis et al. ${ }^{26}$ showed that chain-transfer agents can be used to control the gel content and the molecular weight distribution, and Salazar et al. ${ }^{27}$ used chain-transfer agents to control the molecular weight distribution of emulsion polymerization of styrene under starved conditions. Such extension is however left for a future work.

We sum up the results for both case studies in Appendix B, where we show the improvement obtained by using optimal feed rates compared to keeping the concentration of monomer in the polymer particle close to saturation and by employed average flowrate policies with the same amount of monomer.

\section{CONCLUSION AND FUTURE WORK}


We maximized the mass of polymer produced during semi-batch operation of emulsion polymerization. The concentration of monomer in the particles is constrained to keep the system under diffusion limitation and avoid the gel effect. In order to do so, a detailed model is employed to account for radical diffusion limitations in the polymer particles as a function of the concentration of monomer. Two operating modes are addressed, ab initio, commonly employed in laboratory experiments, and seeded experiments, widely practiced in industry. The results show that the optimal feed flowrates increase the polymer production when compared to the benchmark of keeping the concentration of monomer in the polymer particles close to saturation and to a constant feed rate employing the same amount of monomer.

Further studies are required to have a better prediction of the concentration of monomer in the particles at which radical diffusion limitations start. A small error in this value may make the model drift from the real situation. With a better prediction of this limit, it would be possible to calculate optimal feed flowrates that are closer to the maximum while remaining under starved conditions, thus maximizing the reactor production while keeping a safe operation. Moreover, further investigation is required in order to develop online methods that could improve further the results of this work and be robust to process disturbances.

Our experimental and computational results show that optimal operation under diffusion limitations may almost double the reaction rate of styrene compared to saturated conditions. Such diffusion limitations might be even higher for other emulsion polymerization systems (e.g., methyl methacrylate), and therefore the proposed methodology has the potential to provide even better results. Thus, the investigation of the onset of diffusion limitation for other emulsion polymerization systems and its application to maximize the reactor productivity represents a potential future work.

APPENDIX A: POLYMERIZATION MODEL 
Brunier et al. ${ }^{18}$ presented the full model used in this work. To give an overview of the model and the main implications on the formulation of the dynamic optimization problem in Section 4, we briefly summarize the main equations of the model related to the reaction rate and diffusion limitation.

\section{Mass balances}

The number of moles of residual monomer, $N_{\mathrm{m}}$, is obtained from the monomer mass balance in the reactor:

$$
\frac{d N_{\mathrm{m}}}{d t}=F_{\mathrm{m}}-R_{\mathrm{p}_{\mathrm{p}}} V_{\mathrm{w}}-R_{\mathrm{p}_{\mathrm{w}}} V_{\mathrm{w}}
$$

where $F_{\mathrm{m}}$ is the inlet monomer flowrate and $V_{\mathrm{w}}$ is the total volume of the aqueous phase. The polymerization rate in the aqueous phase $R_{\mathrm{p}_{\mathrm{w}}}$ is given by

$$
R_{\mathrm{p}_{\mathrm{w}}}=k_{\mathrm{p}}[M]_{\mathrm{w}}[R]_{\mathrm{w}}
$$

where $[R]_{\mathrm{w}}$ is the concentration of radicals in the aqueous phase.

The polymerization rate in the particles $R_{\mathrm{p}_{\mathrm{p}}}$ is related to the particle size distribution (PSD). In emulsion polymerization involving only particle growth (no nucleation or coagulation), the PSD can be described by a population balance model as follows ${ }^{28}$ :

$$
\left.\frac{\partial \boldsymbol{F}}{\partial t}\right|_{r, t}+\left.\frac{\partial(\boldsymbol{F} \cdot \boldsymbol{G})}{\partial r}\right|_{r, t}=0
$$

where $\boldsymbol{F}(r, t)$ is the number density of particles of radius between $r$ and $r+\delta r$ at time $t . \boldsymbol{G}(r, t)$ is the growth rate of particles of size $r$, i.e.

$$
\boldsymbol{G}(r, t)=\frac{d r}{d t}=\frac{k_{\mathrm{p}}[M]_{\mathrm{p}} M W}{4 \rho_{\mathrm{m}} N_{\mathrm{A}} \pi} \frac{\bar{n}(r, t)}{r^{2}}
$$

where $\bar{n}(r, t)$ is the average number of radicals per particle of size $r$. 
The polymerization rate in the particles $R_{\mathrm{p}_{\mathrm{p}}}$ is given by:

$$
R_{\mathrm{p}_{\mathrm{p}}}=\frac{k_{\mathrm{p}}[M]_{\mathrm{p}}}{N_{\mathrm{A}}} \int_{0}^{\infty} \bar{n}(r, t) \boldsymbol{F}(r, t) d r
$$

and the density number of monomer-swollen particles per unit volume of latex is given by $N=$ $\int_{0}^{\infty} \boldsymbol{F}(r, t) d r$

The pseudo-bulk model ${ }^{29}$ is used to describe the PSD based on the average number of radicals per particle $\bar{n}(r, t)$. In this model, the particles contain radicals that can coexist for a significant period ${ }^{30}$. In the pseudo-bulk model, the evolution of the average number of radicals in the polymer particles can be obtained using:

$$
\left.\frac{\partial \bar{n}}{\partial t}\right|_{r, t}=\rho_{\mathrm{e}}-k_{\mathrm{des}}(r) \bar{n}(r, t)-2 c(r) \bar{n}(r, t)^{2}
$$

where $k_{\mathrm{des}}$ is the rate coefficient for radical exit, and $c=\frac{k_{\mathrm{t}}}{N_{\mathrm{A}} v_{\mathrm{s}}}$ is the pseudo-first order termination rate coefficient between two chains. The term $\rho_{\mathrm{e}}=k_{\mathrm{e}}[R]_{\mathrm{w}}$ represents the rate of radical entry and $k_{\mathrm{e}}$ the rate coefficient for radical entry from the aqueous phase to the polymer particles.

\section{Diffusion limitations}

When controlling the monomer flowrate, the reaction rate is first directly affected (proportionally) by the increase in the concentration of monomer in the polymer particles. There is also an indirect (inverse) effect of the monomer concentration on the radical concentration, which influences the reaction rate. This is due to changes in monomer/radical diffusivity in the polymer particles.

As a first diffusional limitation, a reduction of the diffusion of long molecules (polymeric radicals) is observed. The onset of such diffusion limitation was identified by Brunier et al. ${ }^{18}$ to be $[M]_{\mathrm{p}}=3.3 \mathrm{~mol} . \mathrm{L}^{-1}$. 
This effect is described by a decrease in the radical termination rate coefficient in the polymer particles ${ }^{31}$. In this work, the following relationship is used:

$$
k_{\mathrm{t}}=k_{\mathrm{t}_{0}} \exp \left[-\alpha_{\mathrm{t}}\left(w_{\mathrm{p}}-w_{\mathrm{p}}^{\text {sat }}\right)\right]
$$

where $w_{\mathrm{p}}^{\text {sat }}$ is the weight fraction of polymer in the particles under saturation with monomer, $\alpha_{\mathrm{t}}$ is a fitting parameter and $w_{\mathrm{p}}$ is the weight fraction of polymer in the particles, given by:

$$
w_{\mathrm{p}}=\frac{V_{\mathrm{p}_{\mathrm{p}}} \rho_{\mathrm{p}}}{V_{\mathrm{p}_{\mathrm{p}}} \rho_{\mathrm{p}}+V_{\mathrm{m}_{\mathrm{p}}} \rho_{\mathrm{m}}}
$$

A glass effect might also take place at very low monomer fractions for polymers with high glass transition temperature. It consists in a decrease in the diffusion of monomer or monomeric radicals in the polymer particles and is thus described by a reduction in the diffusion coefficient of small molecules as follows $\left(V_{\mathrm{f}}<V_{\mathrm{f}_{\mathrm{cr}}}\right)^{32}$ :

$$
D_{\mathrm{p}}=D_{\mathrm{p}_{0}} \exp \left[-0.5\left(\frac{1}{V_{\mathrm{f}}}-\frac{1}{V_{\mathrm{f}_{\mathrm{cr}}}}\right)\right]
$$

where $D_{\mathrm{p}_{0}}$ is the monomer diffusion coefficient in the polymer particles under saturation, $V_{\mathrm{f}_{\mathrm{cr}}}$ is the critical free volume in the particles at the onset of the glass transition and $V_{\mathrm{f}}$ is the free volume in the particles given by:

$$
V_{\mathrm{f}}=V_{\mathrm{f}_{\mathrm{m}}} \frac{V_{\mathrm{m}_{\mathrm{p}}}}{V_{\mathrm{p}}}+V_{\mathrm{f}_{\mathrm{p}}} \frac{V_{\mathrm{p}_{\mathrm{p}}}}{V_{\mathrm{p}}}
$$

where $V_{\mathrm{f}_{\mathrm{m}}}$ and $V_{\mathrm{f}_{\mathrm{p}}}$ are the monomer and polymer contributions to particle free volume, respectively, given by the following semi-empirical relationships ${ }^{31}$ :

$$
V_{\mathrm{f}_{\mathrm{m}}}=0.025+\alpha_{\mathrm{m}}\left(T-T_{\mathrm{gm}_{\mathrm{m}}}\right)
$$




$$
V_{\mathrm{f}_{\mathrm{p}}}=0.025+\alpha_{\mathrm{p}}\left(T-T_{\mathrm{g}_{\mathrm{p}}}\right)
$$

where $\alpha_{\mathrm{m}}$ and $\alpha_{\mathrm{p}}$ are the thermal expansion coefficients of monomer and polymer. $T_{\mathrm{g}_{\mathrm{m}}}$ and $T_{\mathrm{g}_{\mathrm{p}}}$ are the glass transition temperatures of monomer and polymer, respectively.

The investigation of diffusion limitations is essential for the optimization of the process in order to increase the reaction rate while keeping a safe operation. For instance, the reaction rate in eq 2 is proportional to the concentration of monomer in the polymer particles $[M]_{\mathrm{p}}$, indicating that the reaction rate is maximized for high concentrations. However, a deep investigation of the model proves the opposite. Indeed, the number of radicals in the polymer particles $(\bar{n}(r, t))$ decreases when increasing $[M]_{p}$, resulting in a lower reaction rate and possible accumulation of monomer in the reactor. Therefore, calculating the optimal operating conditions requires advanced optimization strategies where the full model is employed and the constraints guaranteeing a safe operation for a high reaction rate are respected.

APPENDIX B: EXPERIMENTS INITIAL CONDITION

\section{Experiment 1}

The initial conditions of "saturated" experiment are:

Mass of initiator: $1.60 \mathrm{~g}$

Mass of polymer: $39 \mathrm{~g}$

Mass of monomer: 0g

Mass of water: $618 \mathrm{~g}$

Figure 7 shows the initial PSD. 


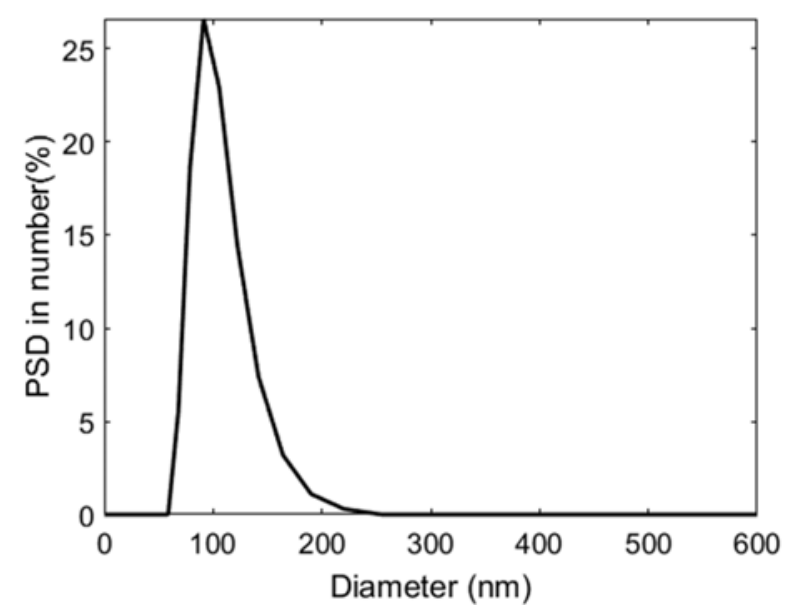

Figure 7: Initial PSD of the "saturated" experiment.

\section{Experiment 2}

The initial conditions of "ab-initio" experiment, at the end of stage 1 are:

Mass of initiator: $0 \mathrm{~g}$ (the initial mass was $1.60 \mathrm{~g}$ )

Mass of polymer: $30 \mathrm{~g}$

Mass of monomer: $8.3 \mathrm{~g}$

Mass of water: $740 \mathrm{~g}$

Figure 8 shows the PSD at the end of stage 1. 


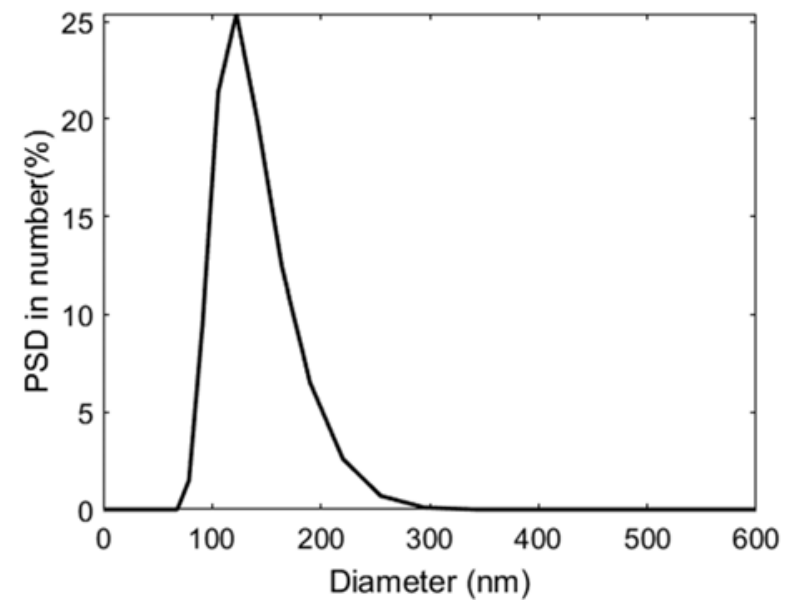

Figure 8: PSD at the end of stage 1 of "ab-initio" experiment.

\section{Experiment 3}

The initial conditions of "seeded" experiment are:

Mass of initiator: $1.60 \mathrm{~g}$

Mass of polymer: $90 \mathrm{~g}$

Mass of monomer: 0g

Mass of water: $658 \mathrm{~g}$

Figure 9. shows the initial PSD. 


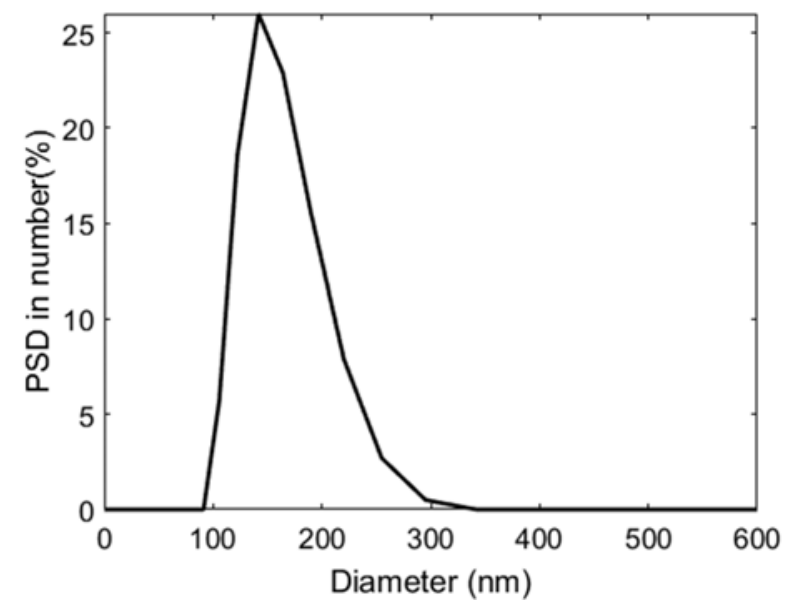

Figure 9: PSD at the end of stage 1 of "seeded" experiment.

\section{APPENDIX B: RESULTS COMPILATION}

We compile in Table 2 the gain obtained by the optimal flowrates compared to the benchmark case and to a constant mean flowrate.

Table 2: Compilation of results.

\begin{tabular}{|c|c|c|c|}
\hline \multicolumn{2}{|c|}{ Case } & "Ab initio" & "Seeded" \\
\hline \multirow{2}{*}{$\begin{array}{l}\text { Calorimetry for } \\
\text { optimal flowrates }\end{array}$} & $\begin{array}{l}\text { Mass of polymer } \\
\text { produced }(\mathrm{g})\end{array}$ & 95 & 190 \\
\hline & 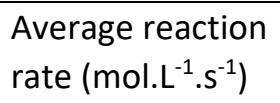 & $2.86 \times 10^{-4}$ & $4.26 \times 10^{-4}$ \\
\hline \multirow{2}{*}{$\begin{array}{l}\text { Simulation for } \\
\text { optimal flowrates }\end{array}$} & $\begin{array}{l}\text { Mass of polymer } \\
\text { produced (g) }\end{array}$ & 78 & 170 \\
\hline & 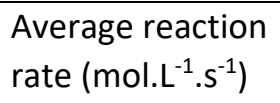 & $2.54 \times 10^{-4}$ & $3.74 \times 10^{-4}$ \\
\hline \multirow{2}{*}{$\begin{array}{l}\text { Simulation for } \\
\text { average flowrate }\end{array}$} & $\begin{array}{l}\text { Mass of polymer } \\
\text { produced }(\mathrm{g})\end{array}$ & 56 & 154 \\
\hline & 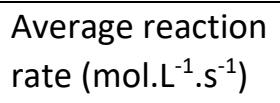 & $1.73 \times 10^{-4}$ & $3.49 \times 10^{-4}$ \\
\hline Simulation for the & Mass of polymer & 59 & 128 \\
\hline
\end{tabular}




\begin{tabular}{|c|c|c|c|}
\hline \multirow[t]{2}{*}{ benchmark } & produced (g) & & \\
\hline & 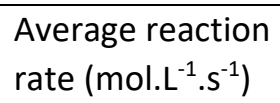 & $1.73 \times 10^{-4}$ & $2.47 \times 10^{-4}$ \\
\hline \multirow{2}{*}{$\begin{array}{l}\text { Improvement } \\
\text { compared to a } \\
\text { average feed rate }\end{array}$} & $\begin{array}{l}\text { Mass of polymer } \\
\text { produced (\%) }\end{array}$ & $39 \%$ & $10 \%$ \\
\hline & $\begin{array}{l}\text { Average reaction } \\
\text { rate (\%) }\end{array}$ & $47 \%$ & $7.2 \%$ \\
\hline \multirow{2}{*}{$\begin{array}{l}\text { Improvement } \\
\text { compared to } \\
\text { benchmark }\end{array}$} & $\begin{array}{l}\text { Mass of polymer } \\
\text { produced (\%) }\end{array}$ & $32 \%$ & $33 \%$ \\
\hline & $\begin{array}{l}\text { Average reaction } \\
\text { rate (\%) }\end{array}$ & $47 \%$ & $51 \%$ \\
\hline
\end{tabular}

\section{AUTHOR INFORMATION}

\section{Corresponding Author}

*E-mail: adel.mhamdi@avt.rwth-aachen.de. Phone: +49 24180 95243. Fax: +49 2418092326

\section{Notes}

The authors declare no competing financial interest.

\section{ACKNOWLEDGMENTS}

This work has received funding from the European Union's Horizon 2020 research and innovation programme under the Marie Skłodowska-Curie grant agreement no.675251. We are thankful to Kevin Dolin-Dolcy at Université de Lyon for helping to run the experiments.

\section{ABBREVIATIONS}

\section{Variables}




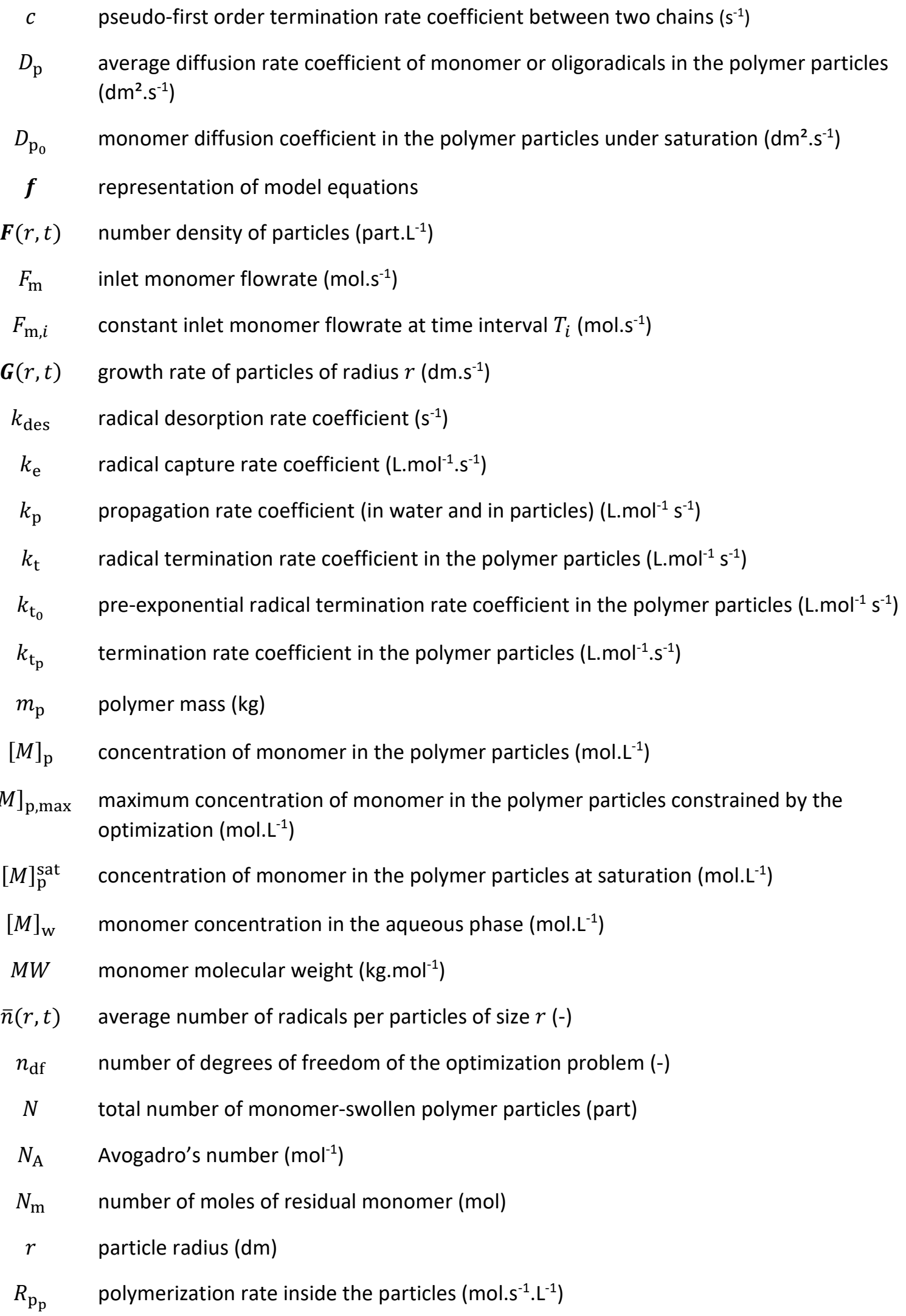




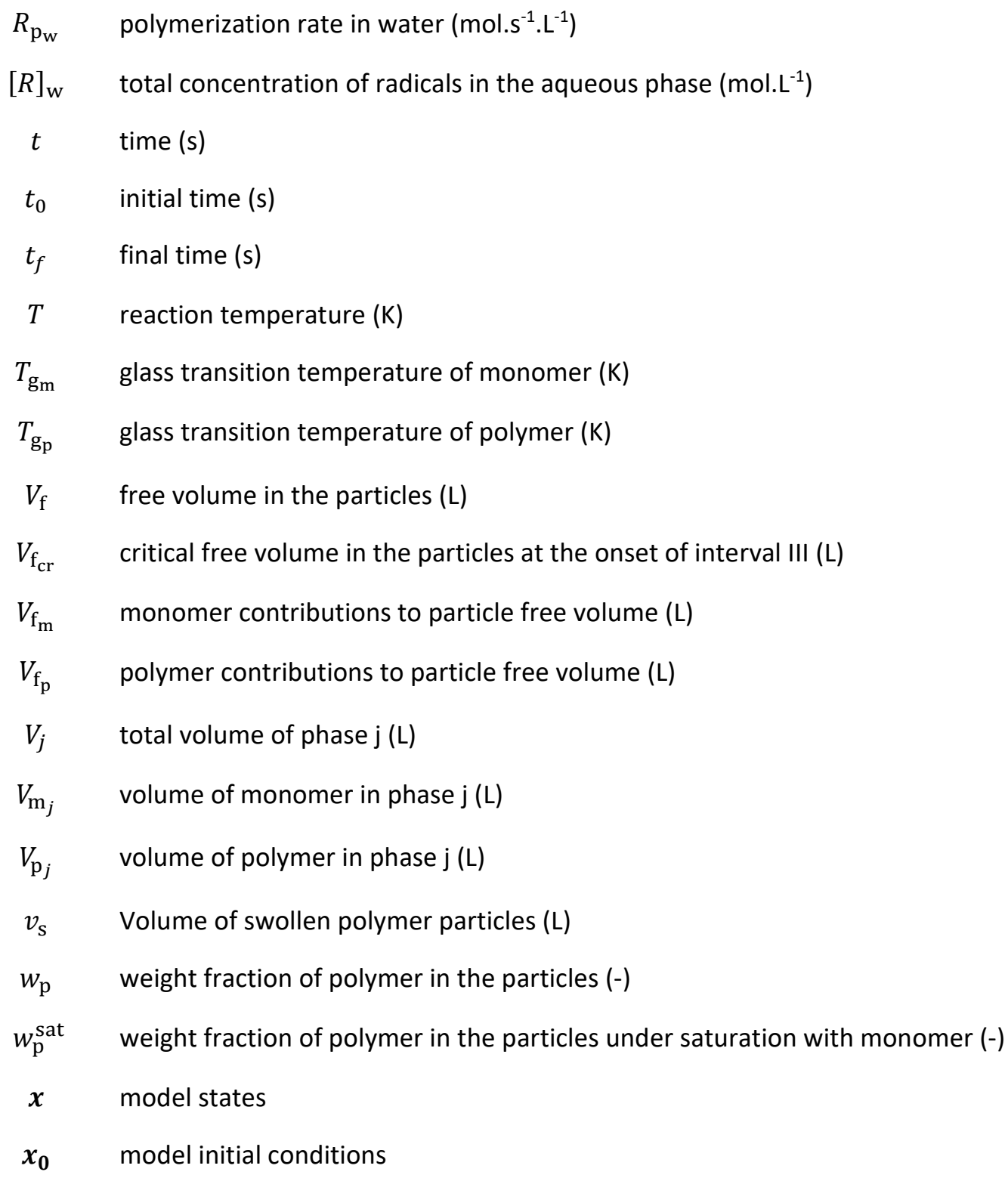

\section{Greek Symbols}
$\alpha_{\mathrm{m}} \quad$ thermal expansion coefficient of the monomer (L.K $\left.{ }^{-1}\right)$
$\alpha_{\mathrm{p}} \quad$ thermal expansion coefficient of the polymer (L.K $\left.{ }^{-1}\right)$
$\alpha_{\mathrm{t}} \quad$ fitting parameters of the radical termination model (-)
$\Delta t_{0} \quad$ initial time interval $\left[t_{0}, t_{1}\right][(\mathrm{s}),(\mathrm{s})]$ 


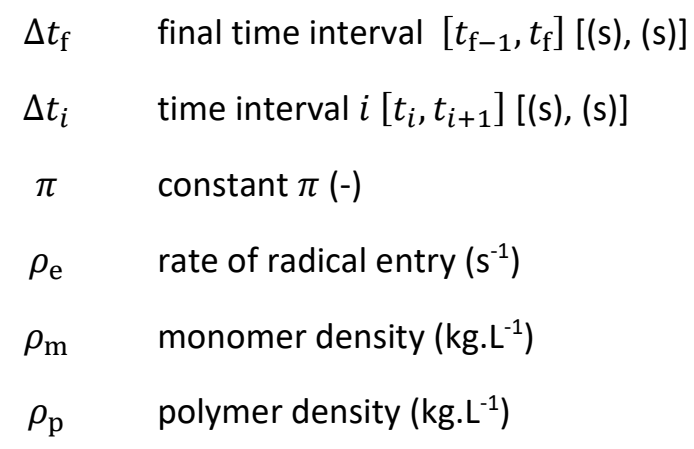

\section{REFERENCES}

1. Asua, J. M., Emulsion polymerization: From fundamental mechanisms to process developments. Journal of Polymer Science Part a-Polymer Chemistry 2004, 42 (5), 1025-1041.

2. Zubov, A.; Naeem, O.; Hauger, S. O.; Bouaswaig, A.; Gjertsen, F.; Singstad, P.; Hungenberg, K. D.; Kosek, J., Bringing the On-Line Control and Optimization of Semibatch Emulsion Copolymerization to the Pilot Plant. Macromolecular Reaction Engineering 2017, 11 (4), 15.

3. Araújo, P. H. H.; Giudici, R., Optimization of semicontinuous emulsion polymerization reactions by IDP procedure with variable time intervals. Computers \& Chemical Engineering 2003, 27 (8-9), 13451360 .

4. Othman, N. S.; Fevotte, G.; McKenna, T. F., Biobjective control of emulsion polymerizations: control of the polymer composition and the concentration of monomer in the polymer particles. Chemical Engineering Journal 2004, 98 (1-2), 69-79.

5. Vicente, M.; Sayer, C.; Leiza, J. R.; Arzamendi, G.; Lima, E. L.; Pinto, J. C.; Asua, J. M., Dynamic optimization of non-linear emulsion copolymerization systems - Open-loop control of composition and molecular weight distribution. Chemical Engineering Journal 2002, 85 (2-3), 339-349.

6. Massebeuf, S.; Fonteix, C.; Hoppe, S.; Pla, F., Development of new concepts for the control of polymerization processes: Multiobjective optimization and decision engineering. I. Application to emulsion homopolymerization of styrene. Journal of Applied Polymer Science 2003, 87 (14), 2383-2396. 
7. Dimitratos, J.; Elicabe, G.; Georgakis, C., Control of Emulsion Polymerization Reactors. Aiche Journal 1994, 40 (12), 1993-2021.

8. Thickett, S. C.; Gilbert, R. G., Emulsion polymerization: State of the art in kinetics and mechanisms. Polymer 2007, 48 (24), 6965-6991.

9. Pokorny, R.; Zubov, A.; Matuska, P.; Lueth, F.; Pauer, W.; Moritz, H. U.; Kosek, J., Process Model for Styrene and n-Butyl Acrylate Emulsion Copolymerization in Smart-Scale Tubular Reactor. Industrial \& Engineering Chemistry Research 2016, 55 (2), 472-484.

10. Sheibat-Othman, N.; Othman, S., Control of an Emulsion Polymerization Reactor. Industrial \& Engineering Chemistry Research 2006, 45 (1), 206-211.

11. Alamir, M.; Sheibat-Othman, N.; Othman, S., Constrained nonlinear predictive control for maximizing production in polymerization processes. leee Transactions on Control Systems Technology 2007, 15 (2), 315-323.

12. Zeaiter, J.; Romagnoli, J. A.; Gomes, V. G., Online control of molar mass and particle-size distributions in emulsion polymerization. Aiche Journal 2006, 52 (5), 1770-1779.

13. Gomes, V. G., Advanced Monitoring and Control of Multi-monomer System in Emulsion Polymerization. Macromolecular Reaction Engineering 2010, 4 (11-12), 672-681.

14. Souza, P. N.; Soares, M.; Amaral, M. M.; Lima, E. L.; Pinto, J. C., Data Reconciliation and Control in Styrene-Butadiene Emulsion Polymerizations. Polymer Reaction Engineering - 10th International Workshop 2011, 302, 80-89.

15. Gentric, C.; Pla, F.; Corriou, J. P., Experimental study of the nonlinear geometric control of a batch emulsion polymerization reactor. Computers \& Chemical Engineering 1997, 21, S1043-S1048.

16. Gentric, C.; Pla, F.; Latifi, M. A.; Corriou, J. P., Optimization and non-linear control of a batch emulsion polymerization reactor. Chemical Engineering Journal 1999, 75 (1), 31-46.

17. Sheibat-Othman, N.; Othman, S.; Boyron, O.; Alamir, M., Multivariable control of the polymer molecular weight in emulsion polymerization processes. Journal of Process Control 2011, 21 (6), 861873. 
18. Brunier, B.; Sheibat-Othman, N.; Othman, S.; Chevalier, Y.; Bourgeat-Lami, E., Modelling particle growth under saturated and starved conditions in emulsion polymerization. Canadian Journal of Chemical Engineering 2017, 95 (2), 208-221.

19. de Buruaga, I. S.; Echevarría, A.; Armitage, P. D.; José, C.; Leiza, J. R.; Asua, J. M., On-line control of a semibatch emulsion polymerization reactor based on calorimetry. AlChE Journal 1997, 43 (4), 1069-1081.

20. Asua, J., Polymer reaction engineering. John Wiley \& Sons: 2008.

21. The MathWorks ${ }^{\odot}$ Inc., Matlab R2016a. Natick, Massachusetts, United States, 2016.

22. Fu, J.; Faust, J. M. M.; Chachuat, B.; Mitsos, A., Local optimization of dynamic programs with guaranteed satisfaction of path constraints. Automatica 2015, 62, 184-192.

23. Gilbert, R. G., Emulsion polymerization: a mechanistic approach. Academic Pr: 1995.

24. Prescott, S. W.; Ballard, M. J.; Gilbert, R. G., Average termination rate coefficients in emulsion polymerization: Effect of compartmentalization on free-radical lifetimes. Journal of Polymer Science Part A: Polymer Chemistry 2005, 43 (5), 1076-1089.

25. Zeaiter, J.; Romagnoli, J. A.; Barton, G. W.; Gomes, V. G.; Hawkett, B. S.; Gilbert, R. G., Operation of semi-batch emulsion polymerisation reactors: Modelling, validation and effect of operating conditions. Chemical Engineering Science 2002, 57 (15), 2955-2969.

26. Plessis, C.; Arzamendi, G.; Leiza, J. R.; Alberdi, J. M.; Schoonbrood, H. A. S.; Charmot, D.; Asua, J. M., Seeded semibatch emulsion polymerization of butyl acrylate: Effect of the chain-transfer agent on the kinetics and structural properties. Journal of Polymer Science Part A: Polymer Chemistry 2001, 39 (7), 1106-1119.

27. Salazar, A.; Gugliotta, L. M.; Vega, J. R.; Meira, G. R., Molecular weight control in a starved emulsion polymerization of styrene. Industrial \& engineering chemistry research 1998, 37 (9), 35823591.

28. Min, K. W.; Ray, W. H., On the Mathematical Modeling of Emulsion Polymerization Reactors. Journal of Macromolecular Science, Part C 1974, 11 (2), 177-255.

29. Ballard, M. J.; Gilbert, R. G.; Napper, D. H., Improved methods for solving the smith-ewart equations in the steady-state. Journal of Polymer Science Part C-Polymer Letters 1981, 19 (11), 533-537. 
30. Smith, W. V.; Ewart, R. H., Kinetics of emulsion polymerization. The journal of chemical physics $1948,16(6), 592-599$.

31. Sajjadi, S., Population balance modeling of particle size distribution in monomer-starved semibatch emulsion polymerization. AlChE journal 2009, 55 (12), 3191-3205.

32. Sundberg, D. C.; Hsieh, J. Y.; Soh, S. K.; Baldus, R. F., Diffusion-controlled kinetics in the emulsion polymerization of styrene and methyl methacrylate. Emulsion Polymers and Emulsion Polymerization 1981, 165, 327-343. 